\title{
Brizoletas: um passeio pela memória, patrimônio cultural e educação
}

\author{
Letícia Baldasso Moraes* \\ Universidade Federal de Santa Catarina \\ Alcyane Marinho** \\ Universidade Federal de Santa Catarina
}

Resumo $\mathrm{O}$ presente artigo teve como objetivos investigar o caso da Brizoleta de uma Instituição de ensino de Porto Alegre e o seu possível tombamento como patrimônio cultural rio-grandense; expor a atual situação das Brizoletas ativas no Rio Grande do Sul, resultantes do projeto "Nenhuma criança sem escola no Rio Grande do Sul", desenvolvido por Brizola na década de 1960; e, ainda, refletir sobre possibilidades levando em consideração o atual panorama da educação. Membros do corpo docente da Instituição foram entrevistados por meio de entrevistas semiestruturadas acerca da Brizoleta. O artigo levanta reflexões sobre uma época na qual a educação era prioridade do Estado e como tal pensamento pode contribuir para a sociedade contemporânea na qual a qualidade da alfabetização ainda não atinge resultados satisfatórios.

PALAVRAS-ChaVE: Brizoleta; Patrimônio cultural; História da educação; Alfabetização; Educação riograndense. 


\title{
Brizoletas: a path of memory, cultural heritage and education
}

\begin{abstract}
This paper aimed to investigate the case of a Brizoleta localizated at an Education Institution and its possible overturning as cultural heritage Rio Grande; display the current status of active Brizoletas results from the project "No child without school in Rio Grande do Sul", developed by Brizola in the 1960s, and also reflect on possibilities taking into account the current situation of education. Faculty members of the Institute were interviewed by a script of questions about Brizoleta. The article raises thoughts about a time in which education was a priority of the State and as such thought can contribute, currently, at which the quality of literacy does not achieve satisfactory results yet.
\end{abstract}

KEYWORDS: Brizoleta; Cultural heritage; Educational history; Literacy; Education at Rio Grande do Sul.

\section{Introdução}

O acúmulo de conhecimento no decorrer do processo de evolução da sociedade possibilitou mudanças substanciais no modo de viver da humanidade e do próprio homem, ampliando horizontes culturais e sociais. Em uma tentativa de buscar e entender fatos ocorridos, o retorno ao passado contribui para encontrar possíveis mudanças na realidade dos dias atuais, com uma melhor compreensão sobre o processo de transformação da sociedade. Conforme Freire (1996), devemos reconhecer que a história é tempo de possibilidade e não de determinismo, que o futuro é problemático, e não inexorável, explicitando que existem muitas oportunidades e que nada está definido antes de acontecer.

Tanto como seres individuais quanto como partes integrantes de uma sociedade, descobrir o trajeto percorrido contribui na compreensão de significado das práticas atuais. Segundo Goellner e Jaeger (2007), a memória não aprisiona ao passado, mas conduz a indagar o presente. Indagando o presente, temos a possibilidade de descontruir hábitos que nos aprisionam em maneiras de pensar que são consideradas naturais, mas são construídas historicamente se consolidando em discursos legitimadores. Estes discursos legitimadores são transversais em diversos aspectos do cotidiano, sendo a crítica uma necessidade dos indivíduos para uma efetiva participação na sociedade. Uma das formas de alicerçar tal criticidade encontra-se na educação, conforme Freire (1987), a educação pode construir sujeitos que se posicionem de forma crítica frente à sociedade, lutando por uma educação igualitária e contextualizada. Educação essa, que, até os dias atuais não conseguiu encontrar seu equilíbrio e potencialidade. A educação e o acesso a diferentes conhecimentos deveriam ser inerentes ao processo de evolução de todos os sujeitos. Contudo, a educação brasileira está distante de ser igualitária, inclusiva ou capaz de produzir sujeitos críticos e indagadores.

A educação brasileira vem buscando sua potencialidade há décadas, tendo um exemplo claro na instauração do projeto das Brizoletas, também conhecidas como 
escolinhas do Brizola, fruto do projeto "Nenhuma criança sem escola no Rio Grande do Sul”, criado por Leonel De Moura Brizola em 1946 e implementadas a partir de 1959. O projeto teve grande repercussão: dos 154 municípios gaúchos, 147 firmaram parcerias com o governo para a construção das escolas (QUADROS, 2005).

Segundo Brizola (2013), entre 1959 e 1962, foram construídas 5.902 escolas primárias, 278 escolas rurais e urbanas e 131 ginásios, colégios e escolas normais, totalizando 6.302 novas instituições. Entretanto, Quadros (2005) analisou os relatórios da Comissão Estadual de Prédios Escolares (CEPE) de 1963 e encontrou números divergentes. Nos quatro anos de governo, construíram-se 1.045 prédios escolares, com 3.360 salas de aula e capacidade para 235.200 alunos; foram iniciados 113 prédios, com 483 salas e capacidade para 33.810 alunos; e planejados 258 prédios, com 866 salas de aula e capacidade para 60.620 alunos. Em 1962, Brizola enviou uma mensagem à Assembleia Legislativa, informando que os convênios com os municípios haviam possibilizado a construção de três mil prédios. Conforme Bemfica (2001), analisando números das séries históricas do IBGE, entre 1958 e 1962, em todas as redes municipais, o aumento no número de matrículas foi menos da metade do indicado na mensagem do governador.

Explicando os números, Bemfica (2001) relembra das dificuldades da educação na época. Muitas interações sociais e políticas vinculadas às heranças de uma sociedade tradicional, oligárquica e patrimonial não evoluíam na mesma velocidade com que Brizola pretendia introduzir a educação em todas regiões. Mesmo com a implementação de novos ambientes escolares, a maioria da população seguia analfabeta. Efetivamente houve um aumento no número de escolas e no acesso à educação, mas não há consenso sobre os números reais.

A análise da evolução do uso de espaços públicos pelos indivíduos permite a contextualização sobre o espaço/tempo ao qual pertencemos. Conhecer o surgimento dos espaços pode remeter a uma melhor interpretação sobre seus significados e representações. Entende-se o espaço público como local destinado ao uso comum e de posse de todos os cidadãos, no qual se desenvolvem atividades coletivas com trocas de experiências entre diferentes grupos sociais (FUNARI, 2001).

Segundo Tomaz (2010), não é possível preservar a memória de um povo sem preservar os espaços por ele utilizados e as manifestações quotidianas de seu viver. Mesmo sendo de valia na construção da história de um povo, algumas Brizoletas estão abandonadas, sem manutenção, conservação e às vezes, sem reconhecimento. Um destes casos reflete-se na situação atual de uma Brizoleta construída dentro de uma Instituição de ensino em Porto Alegre (RS) que se encontra em total abandono e em condições precárias de conservação.

A Brizoleta é um reflexo de um pensamento, no qual se pode melhorar a sociedade por meio da educação. Ela pode ser concebida como a personificação de um projeto que priorizava uma educação de qualidade, podendo ser entendida como símbolo de uma época de mudanças através da educação. Uma construção como essa deve receber o merecido valor, deve ser estudada, analisada e conservada. 
Remanescem, então, algumas perguntas: Ainda existem Brizoletas em funcionamento? O que está sendo feito das Brizoletas existentes no Rio Grande do Sul? Não seria a Brizoleta do Instituto Rio Branco um patrimônio cultural? Qual o significado das Brizoletas para a comunidade que a cerca? Será que o projeto "Nenhuma criança sem escola no Rio Grande do Sul” não poderia servir de inspiração para os governantes atuais? Quais as repercussões, tensões e contradições manifestadas desde a implantação das Brizoletas?

Nesta perspectiva, o presente artigo pretende investigar o caso da Brizoleta do Instituto Rio Branco e o seu possível tombamento como patrimônio cultural riograndense; expor a atual situação das Brizoletas ativas no Rio Grande do Sul e, ainda, refletir sobre possibilidades levando em consideração o panorama da educação atual.

\section{Percurso metodológico}

A pesquisa é caracterizada como qualitativa, sendo realizada em duas etapas metodológicas: entrevistas semiestruturadas e revisão bibliográfica. Segundo Marconi e Lakatos (2003), as entrevistas semiestruturadas possibilitam uma liberdade na obtenção de dados, pois o pesquisador pode analisar os comportamentos gestuais do entrevistado, esclarecer perguntas e especificar significados. Foram entrevistados dez integrantes do corpo docente da Instituição, escolhidos aleatoriamente, independentemente de seu tempo na Instituição ou sua área de conhecimento. As perguntas feitas eram referentes aos seus conhecimentos sobre a Brizoleta e o seu valor para a comunidade. As entrevistas foram realizadas no próprio ambiente escolar, de forma individual.

A realização das entrevistas e as transcrições foram norteadas pelo manual do projeto Garimpando Memórias, desenvolvido pelo Centro de Memória do Esporte (CEME) da Universidade Federal do Rio Grande do Sul (UFRGS). Os entrevistados assinaram uma carta de cessão permitindo a publicação das entrevistas e suas respectivas análises. Para fins de não identificação dos participantes do estudo, seus nomes foram substituídos por outros fictícios.

As redescobertas da história da Brizoleta do Instituto serão contadas por intermédio da metodologia da história oral, que, conforme Pesavento (2013), trata-se de pensar a cultura como um conjunto de significados partilhados e construídos pelos homens para explicar o mundo. Depoimentos constituem uma riqueza inesgotável, servindo não apenas como fonte informativa, mas como instrumento de compreensão ampla e globalizante do significado da ação humana com relação às redes de sociabilidade e com os processos macro culturais que constituem o ambiente, dentro do qual se movem os atores e os personagens da história humana (ALBERTI, 2004).

Abordar historicamente um tema é, por que não pensar assim, construir um passeio por um tempo que é passado e presente, pois, apesar de distante na cronologia, carrega em si proximidades com representações, conceitos, preconceitos, formulações teóricas, construções estéticas, políticas e ideológicas desse tempo que é presente e que é nosso. É procurar nos fragmentos do passado vínculos e persistências com o presente e com o futuro, não no seu desenrolar contínuo e cronológico, mas na descontinuidade dos enlaces que entre eles vão se construindo (GOELLNER; JAEGER, 2006, p.4). 
No segundo momento da pesquisa, para a descoberta das Brizoletas ativas no Rio Grande do Sul foi realizada uma revisão bibliográfica nas bases de dados Scielo, PubMed, Lilacs, Scholar Google e Google. As palavras-chave utilizadas foram: Brizoletas; Escolinhas do Brizola; Plano das Duas Mil. Foram analisadas reportagens de revistas, jornais, artigos acadêmicos e livros.

\section{A Brizoleta da Instituição de ensino de Porto Alegre}

A Brizoleta é uma construção com duas salas e um banheiro, localizada no pátio da educação infantil de uma Instituição de ensino vinculada ao governo do Estado inaugurada em 1930. Encontra-se em situação de abandono, oferecendo risco às crianças a sua volta, pois sua estrutura não é segura. Não existem quaisquer documentos referentes à história da Brizoleta. Ela abrigou alunos durante mais de 40 anos e funcionou até o momento em que começou a decair sem verbas, sendo infestada de cupins, não sendo mais reformada e parece não possuir qualquer valor cultural. Todo esse ciclo simplesmente se perdeu ou nunca foi registrado?

Existem diversas possibilidades para explicar a escassez de documentos. Uma delas é que os arquivos possam ter sido destruídos. De 1963 até os anos atuais, passaram-se quase 60 anos, sendo que deste período, vinte deles foram de ditadura e Brizola foi considerado um inimigo para os militares, tendo sido exilado do país e se refugiado no Uruguai. Há a possibilidade de que os documentos relacionados às escolinhas do Brizola possam ter sido apagados, assim como a possibilidade de que naquela época o registro de atividades e a documentação do que estava sendo feito não eram importantes. Indagações que remanescem sem respostas.

\section{Considerações acerca das entrevistas com os professores}

Nenhum dos entrevistados sabe a data de construção da Brizoleta e não existem relatórios sobre o corpo docente atuante na época, dificultando a descoberta de possíveis integrantes do período pesquisado. Estima-se que tenha sido construída no período entre 1959 e 1963, período em que o projeto "Nenhuma criança sem escola no Rio Grande do Sul” esteve em vigor. Dentre os entrevistados apenas Luciana, professora dos anos iniciais, ministrou aulas na Brizoleta. O professor de Geografia, Mauricio, não sabia sequer o que significava a palavra Brizoleta, nem onde ela estava localizada no ambiente escolar.

Conceição, a diretora, relatou que contatou órgãos do município e do estado para que fosse tomada alguma providência, e os responsáveis por tais órgãos falaram que entrariam em contato. Até o final dessa pesquisa, ela não havia recebido retorno sobre nenhum dos seus questionamentos, seja quanto a reforma, quanto à sua preservação como patrimônio cultural. Sobre o estado de conservação que a Brizoleta se encontra, a diretora enfatizou:

Os cupins tomaram conta, o telhado está caindo porque o forro era tipo um cartonado, então aquilo ali desabou com o tempo [...]. Tem outro agravante que são aqueles garapuvus, planta cuja raiz não vai para baixo do solo, mas para cima. É muito perigoso em dia de vento ou de chuva, de cair por cima do prédio. 
Além do perigo eminente da Brizoleta, deve-se considerar que ela está inserida em um ambiente escolar no Brasil, tornando-se um espaço relevante para o aumento da capacidade física. Assim, alguns professores veem a Brizoleta como aumento do espaço utilitário. Conforme a professora de Matemática, Cintia: "Com ela teríamos mais salas de aula ou mais uma sala de recursos ou até uma sala multiuso ou de jogos. Tanto para o ensino fundamental quanto para o médio, tudo que nós temos de espaço educativo deveríamos poder utilizar". Nota-se a necessidade de espaços para a prática de atividades que ultrapassassem as salas de aula convencionais.

As aulas em ambientes diferentes propiciam novidades para as crianças, podendo gerar maior interesse e vontade de participação nas atividades. Podem traduzirse em experiências marcantes, pois serão consideradas como uma situação contrária à rotina, contrária à normalização das aulas que ocorrem sempre no mesmo ambiente, girando em torno da mesa, cadeira e quadro negro. Conforme Freire (1996), se o aprendiz desenvolver uma curiosidade crescente, mais aprenderá e mais buscará conhecimento.

De acordo com Marisa, professora de História: "Foi um projeto maravilhoso. Se a escola tivesse respeitado, assim como os professores que trabalhavam naquela época, talvez hoje não precisássemos brigar por projetos. Ela é um patrimônio histórico". Segundo Carla, professora de Ciências: "Valor para mim é o valor histórico: não gostaria de perder, ou dar espaço para outra construção, mas, sim, reformar ou restaurar para que servisse como um espaço de educação e história do estado". Pode-se notar que alguns professores veem a Brizoleta como um prédio histórico digno de conservação, mas, também, veem-na como o ganho ou a perda de um espaço utilitário.

É importante ressaltar a importância da comunidade na construção e na manutenção dos espaços. Conforme Melo (2002), os governantes devem trabalhar em conjunto com a população, e não para ela. Os cidadãos também devem ser responsáveis pela complexa administração envolvendo os espaços públicos. Tais espaços devem ser para benefício de todos que o cercam, sendo tratados como importantes meios de sociabilização.

Quando perguntados sobre o que deveria ser feito em relação à Brizoleta, a maior parte dos entrevistados demonstrou empatia para a restauração ou reforma da mesma. Segundo Carla: "Eu acho que ela (Brizoleta) deveria ser preservada, reformulada por uma equipe de arquitetos que trabalhassem com preservação e restauração para mantermos a história viva". Nota-se uma vontade de restauração, uma vontade de preservação, mas os professores ainda não se mobilizaram para que isso acontecesse. No momento em que a pesquisa foi realizada, a diretora foi a única motivada buscando alternativas para reverter tal situação.

Para o sucesso de intervenção em espaços públicos, Melo (2002) propõe que a comunidade envolvida esteja presente desde o início da implantação do projeto, dialogando durante o processo de consolidação do projeto para que se torne parte integrante e indispensável, auxiliando no cotidiano e manutenção de tais espaços. É de suma importância que as decisões sempre levem em consideração os desejos da comunidade. No caso da Brizoleta da Instituição, seria auspiciosa uma mobilização 
por parte dos professores, dos alunos, e da comunidade que vive esse ambiente escolar, mobilizando-se de forma que possam chamar a atenção de entidades que auxiliem na situação atual.

\section{O possível tombamento da Brizoleta como patrimônio cul- tural}

Não existe consenso entre os pesquisadores, mas vem utilizando-se o conceito patrimônio cultural ao invés de patrimônio histórico por sua maior maleabilidade. Refere-se ao conjunto de identidades coletivas, contrastando-se ao termo patrimônio histórico, cujo conceito concentra-se mais na materialidade, em algo sólido e indestrutível (FONSECA, 2001; FUNARI, 2001).

Conforme Tomaz (2010), a preservação de bens patrimoniais deve ter por finalidade conservar traços da vida comum, quotidiana, e mostrar como vivia a sociedade em determinada época. E o que torna um bem como um patrimônio cultural é a atribuição de sentidos ou significados que tal bem possui para um determinado grupo social, justificando sua preservação. Para melhor explicitação sobre patrimônio histórico, o decreto Decreto-Lei no 25, de 30 de novembro de 1937 do Instituto de Patrimônio Histórico e Artístico Nacional (IPHAN) afirma:

Art. $1^{\circ}$. Constitui o patrimônio histórico e artístico nacional o conjunto dos bens móveis e imóveis existentes no país e cuja conservação seja de interesse público, quer por sua vinculação a fatos memoráveis da história do Brasil, quer por seu excepcional valor arqueológico ou etnográfico, bibliográfico ou artístico.

Salienta-se que as Brizoletas possuem uma ligação latente a fatos memoráveis da história da educação do Brasil e do Rio Grande do Sul, sendo ícone de uma geração. Conforme Tomaz (2010), quando se depara com um espaço de relevância histórica, ele deve oportunizar que sentimentos do passado sejam vivenciados, trazendo sensações do presente. As construções não se traduzem no material físico que são constituídas, mas na sua gama de vivências e significados.

Conforme o Decreto no 31.049, de 12 de janeiro de 1983, o Instituto do Patrimônio Histórico e Artístico do Estado do RS (IPHAE) decreta que devem ser tombados "bens de valor cultural que possuam valor histórico, artístico, arqueológico, etnográfico, bibliográfico ou artístico, bem como sítios urbanos, monumentos e paisagens". Podem ser tombados bens móveis (acervos museológicos, coleções iconográficas etc.) ou bens imóveis. No caso da Brizoleta, o tombamento seria classificado como um bem imóvel por tratar-se de uma edificação. Não são todos os imóveis antigos que podem ou devem ser tombados, existem circunstâncias que devem ser analisadas e a respeito da importância de tal tombamento. Citando a mitologia grega, Lourenço (1999, p. 20) afirma: "Tombar é uma explicitação de valores, um desejo de se driblar o tempo, Cronos, o deus capaz de destruir seus próprios filhos". Deve-se questionar se a construção realmente deve ser indicada a tombamento e se terá importância para as gerações futuras. 
Como se pode analisar por meio de diferentes autores e decretos leis, a Brizoleta da Instituição é mais do que uma simples construção, ela é o símbolo de uma época inteira. É resultado das tentativas de melhorar a sociedade pela educação, alfabetizando crianças riograndenses de forma igualitária, tornando o processo de alfabetização menos exclusivo. Por mais que seus objetivos não tenham sido totalmente alcançados, as Brizoletas podem servir de inspiração para as futuras gerações na busca por uma educação de qualidade. Para tanto, deve ser tombada como patrimônio cultural, explicitando seu devido valor.

\section{Brizoletas ativas pelo Rio Grande do Sul}

Para o levantamento das Brizoletas existentes no Rio Grande do Sul, foi realizada uma revisão bibliográfica no período de 2012 a 2017. Tais levantamentos resultaram em endereços de e-mails de escolas no interior do Rio Grande do Sul, com os quais a pesquisadora entrou em contato. Contudo, a maior fonte de informações foi por meio de jornais locais virtuais, que funcionam como fontes disseminadoras de informações relevantes para suas comunidades.

Existem Brizoletas ativas pelo Rio Grande do Sul, mas nem todas atuam como escolas. Pode-se notar dificuldades para obtenção de verbas para sua manutenção, com algumas decaindo a cada ano, tornando-se perigosas para os usuários que a frequentam.

$\mathrm{Na}$ cidade de Barra Funda (RS) em 2010, foi desenvolvido um projeto com as turmas do $9^{a}$ ano da Escola Municipal Barra Funda, no qual foi trabalhado o resgate histórico da educação do município, principalmente em relação à história das Brizoletas. O projeto teve a participação das professoras das turmas do $9^{\circ}$ ano e da Secretaria de Educação do município. A Brizoleta foi reformada e mudada de lugar, mas manteve suas características arquitetônicas iniciais e está aberta para visitações.

Em Passo Fundo (RS) a Brizoleta foi restaurada por especialistas em conservação e recuperação de prédios históricos, mantendo suas características originais. Ela é utilizada para abrigar projetos desenvolvidos para a comunidade, como a realização de cursos de capacitação profissional, e atividades do Departamento de Atendimento da Terceira Idade e do Clube de Mães.

Duas Brizoletas, localizadas em Gramado (RS), estão no processo de tombamento como patrimônio cultural pelo IPHAE. Segundo o site do município, foram as primeiras tombadas do Estado. Em contato com um responsável do IPHAE, foi relatado que o processo não foi concluído. $\mathrm{O}$ tombamento das Brizoletas facilita a captação de recursos para restauração dos prédios e preservação do seu entorno.

No Vale do Caí, região central do Rio Grande do Sul, há uma Brizoleta em funcionamento e conservada. Ela é usada como espaço utilitário da escola, servindo como sala da direção, sala dos professores, biblioteca e audiovisual. O seu estado de conservação é de qualidade e ela abriga os indivíduos em segurança.

No interior do município de Erechim (RS), há uma Brizoleta exatamente como foi construída 53 anos atrás. A Escola Estadual preserva suas características 
iniciais e possui duas salas de aula, secretaria, sala de informática, refeitório, biblioteca e sala de vídeos. Com $180 \mathrm{~m}^{2}$ em uma área de $40 \mathrm{mil} \mathrm{m}^{2}$ a escola possui onze alunos matriculados do $1^{\circ}$ ao $5^{\circ}$ ano. Durante as férias, alunos, ex-alunos e a comunidade auxiliam na manutenção para que todos possam utilizar o espaço.

Em Mato Perso (RS) existe uma Brizoleta funcionando normalmente, com 81 alunos e nove professores. O conflito atual da direção é pela municipalização da escola, passando, assim, as responsabilidades de manutenção para o município de Flores da Cunha. A prefeitura se prontificou em modernizá-la, mas, até então, nada foi feito a respeito.

A Brizoleta localizada em Rincão Del Rey (RS) está em funcionamento com uma turma de alunos do oitavo ano e uma do quarto ano. Também abriga alunos do programa "Mais Escola", uma estratégia do Ministério da Educação para indução da construção da agenda de educação integral nas redes estaduais e municipais de ensino ampliando a jornada escolar. A escola espera há anos pela ajuda do Estado para reformas. Ativa e abrigando dezenas de crianças, apresenta assoalho corroído, telhas, barrotes e rede elétrica danificados e a madeira infestada de cupins, tendo uma sala interditada. Seu estado foi declarado como emergencial por especialistas em 2011, mas até 2017 nenhuma medida foi tomada.

Também existem Brizoletas ativas nas cidades de Rodeio Bonito, Saltinho e Guaporé. Outras Brizoletas podem permanecer em funcionamento, mas não há disponibilização de suas informações. Achados deste estudo mostram que existem Brizoletas em funcionamento, algumas conservando a mesma forma da época de construção. Outras são utilizadas como espaços utilitários, abrigando a comunidade. É de se deleitar a certeza de que alguns patrimônios culturais estejam conservados e servindo como incentivo à educação e à união de indivíduos.

\section{Possibilidades e novos horizontes}

Passados mais de cinquenta anos, o analfabetismo e a deficiência na qualidade da educação continuam sendo uma adversidade para o país. Segundo a Avaliação Nacional da Alfabetização (ANA) de 2014, o Rio Grande do Sul está entre os Estados com a menor porcentagem de estudantes em fase de alfabetização capazes de escrever no nível desejado para sua idade. Somente 7,53\% dos estudantes do $3^{\circ}$ ano do Ensino Fundamental atingiram o melhor nível de escrita definido pelo MEC - porcentagem menor que a média nacional de 9,88\%.

A maior parte dos países desenvolvidos eliminou o analfabetismo no início do século 20. O Brasil ainda acumula desigualdades e ausências. A escolaridade média da população é baixa e o analfabetismo funcional é elevado [...]. Mais grave é que estar na escola não garante o aprendizado. Ofertar um ensino de qualidade continua sendo o grande desafio da agenda dos educadores (FAGNANI, 2014, p. 100).

A busca por uma educação duradoura e de qualidade que incite os alunos a buscarem mais conhecimento e aprofundarem seus estudos ainda é um objetivo busca- 
do por muitos professores e alguns governantes. Será que o projeto "Nenhuma criança sem escola no Rio Grande do Sul” não poderia inspirar os dias atuais?

Deve-se lutar por uma educação mais individualizada, com maior atenção as particularidades dos alunos, considerando o contexto sociocultural no qual estão inseridos. Existem muitas escolas com excesso de alunos, falta de sala de aulas, falta de materiais e, em alguns casos, falta de respeito pela heterogeneidade dos alunos. Não seria auspiciosa a criação de escolas menores, nas quais os professores tivessem uma maior intimidade com alunos e pudessem educar de forma mais contextualizada, mais próxima à situação em que as crianças vivem?

Segundo Freire (1987), a educação e a cultura devem andar juntas em uma relação dialética e prática, na qual a realidade da criança seja o ponto inicial da estruturação da sua educação. Freire (1987) sempre acreditou e defendeu uma educação que levasse em consideração o ambiente sociocultural no qual a criança é inserida e sua contextualização através das metodologias utilizadas. Em outras palavras, deve-se respeitar e englobar o máximo possível do ambiente que a criança vive, trazendo essa prática para o contexto escolar.

A partir das relações do homem com a realidade, resultantes de estar com ela e de estar nela, pelos atos de criação, recriação e decisão, vai ele dinamizando o seu mundo. Vai dominando a realidade. Vai humanizando-a. Vai acrescentando a ela algo de que ele mesmo é fazedor. Vai temporalizando os espaços geográficos. Faz cultura (FREIRE, 1983, p.43).

Segundo De Almeida (2008), Freire teve sua oportunidade de fazer a diferença no nordeste do Brasil na década de 1960, na mesma época, Brizola realizava seu projeto no Rio Grande do Sul. Nos extremos e independentemente um do outro. Freire (1987) acreditava que a escola deveria ser um lugar que inspirasse os alunos a pensar de uma forma diferente da educação bancária e que pudessem tornar-se parte integrante e criativa da sociedade para que fizessem a diferença, saindo do seu status como oprimidos. Brizola acreditava que a escola deveria ir ao encontro dos seus alunos, e que se levasse em consideração o ambiente no qual estavam envoltos, eles poderiam ser mais críticos e melhorariam o Estado como partes integrantes e questionadoras. Nota-se que a libertação dos homens só pode ser atingida por meio da educação e da socialização. A educação tem um poder transformador e pode problematizar a situação dos homens em relação ao mundo; gerar cidadãos curiosos, que busquem por mais conhecimento, que exijam direitos iguais e que entendam para onde e como suas vidas estão sendo conduzidas.

Conforme Brandão (2015), a qualidade de ensino acaba por adquirir formatos próprios. Os professores poderiam sentir-se mais encorajados a trabalhar de maneira mais eficiente, mais inclusiva e com melhor eficácia se pudessem ter uma maior proximidade com seus alunos. Como se pode depreender em alguns dos exemplos supracitados, as Brizoletas podem ser utilizadas como uma forma de oferecer educação de qualidade, de integrar-se na comunidade, e resgatar valores da história riograndense. A educação em Brizoletas nas cidades do interior fortalecem o vínculo local e a união em pequenas comunidades. 
Parece interessante o atrevimento de pensar por que há mais Brizoletas conservadas e em atividade em cidades do interior do Rio Grande do Sul do que na capital, em Porto Alegre? Seria a cultura compartilhada nestas localidades mais sensível à preservação histórico-cultural do que em cidades maiores, como Porto Alegre? Fica no ar mais uma inquietação para próximos estudos.

\section{Concluindo...}

Muitas memórias passam por dentro de paredes. Cada casa, cada escola, cada construção tem sua história, isso é inegável. $\mathrm{O}$ artigo em questão tentou trazer à tona as Brizoletas, esquecidas ou até desconhecidas por muitos.

Ainda existem Brizoletas ativas pelo estado do Rio Grande do Sul. Não há números exatos, pois é árdua a obtenção de documentos que obtenham o registro das escolas que foram construídas, e mais árdua ainda a obtenção de registros das Brizoletas ativas. Não existe uma rede de dados específica para o registro e classificação das Brizoletas.

Se as Brizoletas fossem tombadas como patrimônio cultural, teriam mais ensejo de captar verbas para sua manutenção, mais atenção por parte da comunidade historiadora e receberiam o seu devido valor cultural e histórico. Partindo da análise do Decreto-Lei $\mathrm{n}^{\circ} 25$, de 30 de novembro de 1937, em conjunto com arquivos do IPHAE, além da literatura científica sobre o tema, pode-se concluir que é lei preservar e resgatar a Brizoleta como patrimônio cultural.

A Brizoleta localizada na Instituição de ensino de Porto Alegre é exemplo de uma história transitando entre gerações, e a sua problematização deve ser levada adiante, podendo ser pelo intermédio da comunidade que a envolve. Os professores e os integrantes da parte administrativa podem mobilizar-se para que tais diálogos sejam criados e atitudes tomadas.

As Brizoletas são portadoras de significados, de tentativas, de promessas de uma educação acessível a todos. Que elas sejam lembretes de que com criatividade, força de vontade e determinação, pode-se melhorar a educação, torná-la mais universal, mais igualitária e mais transformadora.

Com mudanças substanciais na educação, pode-se entender o passado, aproveitar o presente de forma mais plena e caminhar rumo a um futuro digno, no qual a educação seja disponível para todas as crianças no território brasileiro, mesmo no ponto mais longínquo que se possa imaginar. Outros estudos devem ser feitos acerca das Brizoletas para um maior conhecimento sobre sua história, seus usos atuais e sua importância para a história da educação tanto estadual quanto nacional.

\section{Referências}

ALBERTI, V. Manual de história oral. Rio de Janeiro: FGV Editora, 2004. 236p.

BEMFICA, F. C. M. Desconstruindo mitos. Mestrado em História. Campinas: UNICAMP, 2001. 
BRANDÃO, Z.; CARVALHO, C. P. Qualidade do ensino, balanço de uma década de pesquisas. Educação e Pesquisa, São Paulo, v. 36, n. 131, p. 445-157, abr./ jun., 2015. Disponível em <http://dx.doi.org/10.1590/ES0101-73302015147625>. Acesso em 29 mar. 2017.

BRIZOLA, J. Escola de Tempo Integral: a semente do amanhã. 2a ed. Porto Alegre: Assembleia dos Gaúchos, a casa dos grandes debates, 2013.60p.

DE ALMEIDA, A. L. Paulo Freire e a educação popular no nordeste: um ensaio sobre a vitória dos vencidos, nos primeiros anos da década de 60. Revista de Educação Popular, v. 2, n. 1, 2008.

FAGNANI, E. Além da agenda endógena da educação: propostas para a construção coletiva de um projeto de desenvolvimento. Educação e Sociedade, v. 35, n. 129, p. 999-1026, 2014.

FONSECA, M. C. L. Referências culturais: base para novas políticas de patrimônio. Políticas sociais acompanhamento e análise, p. 111-120, 2001.

FREIRE, P. Educação como prática da liberdade. 14ª edição. Rio de Janeiro: Paz e Terra, 1983. $150 \mathrm{p}$.

FREIRE, P. Pedagogia do Oprimido. $17^{\circ}$ edição. Rio de Janeiro: Paz e Terra, 1987.110p.

FREIRE, P. Pedagogia da Autonomia: saberes necessários à prática educativa. $25^{\text {a }}$ edição. Rio de Janeiro: Paz e Terra, 1996. 60p.

FUNARI, P. P. A. Os desafios da destruição e conservação do patrimônio cultural no Brasil. Trabalhos de antropologia e etnologia, v. 41, n. 1/2, p. 23-32, 2001.

GOELLNER, S. V.; JAEGER, A. A. Garimpando memórias: esporte, educação física, lazer e dança. Porto Alegre: Universidade Federal do Rio Grande do Sul, 2007. 178p.

IPHAE. Decreto-Lei no 31.049, de 12 de janeiro de 1983.

IPHAN. Decreto-Lei no 25, de 30 de novembro de 1937.

LOURENÇO, M. C. Bens imóveis tombados ou em processo de tombamento da USP. Comissão do patrimônio cultural. Patrimônio e novos desafios. São Paulo: USP, p. 12-22, 1999.

MARCONI, M. A.; LAKATOS, E. M. Fundamentos da metodologia científica, $5^{\circ}$ edição. São Paulo, editora Atlas, 2003.

MELO, V. A. Manual para otimização da utilização de equipamentos de lazer. Serviço social do comércio. Rio de janeiro, 2002.

PESAVENTO, S. J. História \& história cultural. São Paulo: Autêntica, 2013.136p.

QUADROS, C. As Brizoletas cobrindo o Rio Grande: a educação pública no Rio Grande do Sul durante o governo de Leonel Brizola (1959-1963). Editora UFSM, 2003. 116p.

QUADROS, C. Marcas do tempo: imagens e memórias das Brizoletas. Santa Maria: Unifra, 2005. 120p.

TOMAZ, P. C.A Preservação do Patrimônio Cultural e sua Trajetória no Brasil. Revista Fênix, revista de História e Estudos Culturais 7, v.7, n.2, p. 1-12, 2010.

* Mestre em Educação Física pela Universidade Federal de Santa Catarina, Florianópolis, Santa Catarina, Brasil.

** Professora doutora do Centro de Ciências da Saúde e do Esporte (CEFID) da Universidade do Estado de Santa Catarina, Florianópolis, Santa Catarina, Brasil. 


\section{Correspondência}

Letícia Baldasso Moraes - Centro de Ciências da Saúde e do Esporte. Rua Pascoal Simone 358, Coqueiros. CEP: 88080-350. Florianópolis, Santa Catarina, Brasil.

E-mail: leticia.baldasso@outlook.com - alcyane.marinho@hotmail.com

Recebido em 26 de maio de 2017

Aprovado em 01 de novembro de 2017 
